\title{
Lower respiratory tract infections: serious or self-limiting acute cough?
}

\author{
*Jochen W Calsa, \\ Pieter-Jan Beckers ${ }^{a}$, \\ Leon de Bocka, \\ a Department of General Practice, \\ Maastricht University, Maastricht, \\ Netherlands \\ ${ }^{*}$ Correspondence: \\ Dr Jochen Cals \\ Department of General Practice, \\ Maastricht University, \\ PO Box 616 \\ Maastricht, \\ $6200 \mathrm{MD}$ \\ Netherlands \\ Tel: +31433882441 \\ Fax: +31433619344 \\ E-mail: j.cals@hag.unimaas.nl
}

18th September 2010

C 2010 Primary Care Respiratory Society UK. All rights reserved

\section{Dear Sir,}

We enjoyed reading Evertsen et al.'s paper in the most recent issue of the PCRJ.' Their work clearly illustrates that the identification and management of adults with respiratory tract infections (RTIs) remains a major challenge for primary care physicians.

The authors sought to find predictors of disease labels used by clinicians to classify RTIs, including pneumonia. As important as this may be in studying links between treatment and outcomes, it may also prove useless in daily practice where there is clear evidence of between-practitioner variation in antibiotic use. ${ }^{2}$ Knowing this, a multilevel analysis to correct for clustering by physician could, and perhaps should, have been performed.

A staggering $93 \%$ of patients labelled with acute bronchitis were treated with antibiotics in their study, ${ }^{1}$ even though current evidence shows hardly any benefit from antibiotics for this condition. This suggests that labelling, or ordering a chest X-ray for that matter, barely influenced the initial decision to prescribe for patients with lower respiratory tract infections (LRTIS) - a point stressed in the accompanying editorial by Newbegin and Macfarlane. ${ }^{3}$ As the authors correctly state, this once again underpins the potential influence of patientrelated factors, including patient pressure to prescribe. ${ }^{4}$

The study suggests that fever and any abnormality on auscultation are the best predictors for labeling an acute RTI as pneumonia. Based on Table 1, we dare to say that this seems misguided. In this analysis, pneumonia-labelled patients were compared to nonpneumonia patients. However, the latter group also included patients with common cold, rhinosinusitis and other upper RTIs. Nevertheless, the real challenge is in differentiating pneumonia from other LRTIs such as acute bronchitis. We calculated the odds ratios (ORs) for relevant symptoms for this comparison (pneumonia versus acute bronchitis). The ORs for rhonchi and wheezes are non-significant at $0.94(95 \% \mathrm{Cl}$ : $0.61-1.45)$ and $1.32(95 \% \mathrm{Cl}$ : $0.86-2.04$ ) respectively. Thus, the importance of abnormal breath sounds was generally overestimated. Only rales remained significant $(p<0.0001)$, which is in line with diagnostic studies using chest $\mathrm{X}$-ray as the golden standard test for pneumonia. ${ }^{5}$

Unintentionally untreated pneumonia patients do recover in primary care. ${ }^{6}$ Managing the patient rather than treating a diagnosis appears safe and effective in general practice. Perhaps we need to look at the spectrum of all coughing patients (with pneumonia and bronchitis) as a continuum from self-limiting to serious LRTI, while focussing on symptoms and not disease labels. We need prospectively-validated prediction rules and possibly inexpensive biomarkers to aid clinicians to safely rule out serious LRTI in most patients and withhold antibiotic treatment in that majority, while preserving these valuable drugs for the minority of serious infections. The pan-European GRACE research network (www.graceIrti.org) is currently performing the largest ever diagnostic and prognostic study in LRTI in $>3000$ patients in 13 European countries, and this will hopefully fill in the evidence gap that exists in the management of this 'bread and butter' condition in primary care.

\section{Conflict of interest declaration} None.

\section{References}

1. Evertsen J, Baumgardner DJ, Regnery A, Banerjee I. Diagnosis and management of pneumonia and bronchitis in outpatient primary care practices. Prim Care Resp J 2010;19(3):237-41. http://dx.doi.org/10.4104/ pcrj.2010.00024

2. Stocks N, Fahey T. Labelling of acute respiratory illness: evidence of between-practitioner variation in the UK. Fam Pract 2002;19(4):375-7. http://dx.doi.org/10.1093/fampra/19.4.375 
3. Newbegin C, Macfarlane J. Diagnosing pneumonia accurately in the community - is it necessary? (Editorial). Prim Care Resp J 2010;19(3):200-01. http://dx.doi.org/10.4104/pcrj.2010.00051

4. Davey P, Pagliari C, Hayes A. The patient's role in the spread and control of bacterial resistance to antibiotics. Clin Microbiol Infect 2002;8(Suppl 2):43-68. http://dx.doi.org/10.1046/j.1469-0691.8.s.2.6.x

5. Hopstaken RM, Muris JWM, Knottnerus JA, Kester ADM, Rinkens PELM, Dinant
GJ. Contributions of symptoms, signs, erythrocyte sedimentation rate and Creactive protein to a diagnosis of pneumonia in acute lower respiratory tract infection. Br J Gen Pract 2003;53:358-64.

6. Hopstaken RM, Coenen S, Butler CC. Treating patients not diagnoses: challenging assumptions underlying the investigation and management of LRTI in general practice. I Antimicrob Chemother 2005;56(5):941-3. http://dx.doi.org/10.1093/jac/dki330

Available online at http://www.thepcrj.org

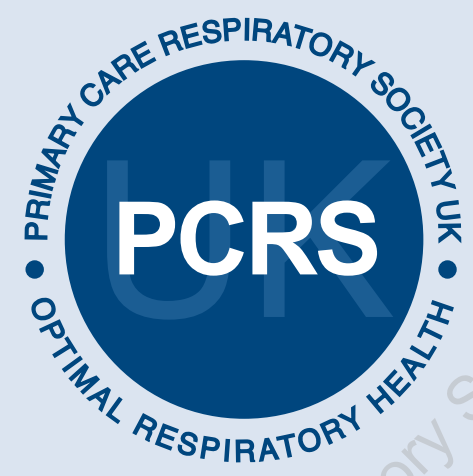

\section{PCRS-UK National Primary Care Conference 2011}

\section{Delivering Quality Respiratory Care Today: Raising the Bar}

\section{7th and 8th October 2011 \\ Telford International Centre, Telford}

For more information and to register your interest in attending email us at info@pcrs-uk.org

Full details and conference programme available soon on our website

www.pcrs-uk.org 